\title{
Gerenciamento de uma Sala de Cinema, no Interior do Estado de Minas Gerais, com base no Custeio Direto
}

\author{
Alaerte Gomes de Assis Neto \\ Mestrado em Ciências Contábeis e Atuariais pela Pontifícia Universidade Católica de \\ São Paulo - PUC/SP \\ Gerente Financeiro/Contábil na Guaxupé Promoções e Eventos Ltda \\ R Cap Joaquim Norberto, 77. Centro. Guaxupé/MG. CEP: 37800-000 \\ E-mail: alaerteneto1@bol.com.br \\ Natani Andreza Jesus Oliveira \\ Pontifícia Universidade Católica de São Paulo - PUC/SP \\ E-mail: natanioliveira029@gmail.com \\ Fernando de Almeida Santos \\ Pós-Doutorado em Ciências Contábeis pela Pontifícia Universidade Católica de São \\ Paulo - PUC-SP \\ Professor na Pontifícia Universidade Católica de São Paulo - PUC/SP \\ Campus Monte Alegre. Perdizes. São Paulo/SP. CEP: 05014901 \\ E-mail: almeidasantos@pucsp.br
}

\section{RESUMO}

Com a competitividade existente no mercado, adquirir conhecimento sobre gestão de custos consiste em um diferencial sobre os concorrentes. O objetivo desta pesquisa é analisar os dados obtidos com a aplicação do método de custeio direto em uma sala de cinema para construir uma forma de apurar seus custos. A metodologia da pesquisa é documental, com a utilização de informações que não haviam sido analisadas, descritiva e de caráter qualitativo. Para validar e exemplificar os conceitos apresentados, utilizou-se de um estudo de caso com a aplicação de um questionário e do método de custeio direto. Conclui-se que, de acordo com a metodologia utilizada, o gestor passou a ter informações de quais foram os gastos diretos e indiretos no período analisado, a margem de contribuição unitária dos itens comercializados e o ponto de equilíbrio da empresa. A contribuição do trabalho consiste na adaptação do método de custeio direto para utilização em uma sala de cinema, onde o gestor pode buscar reduzir os gastos, aumentar a margem de lucro e, com isso, contribuir para o crescimento da empresa.

Palavras-chave: Gestão de Custos. Tomada de Decisão. Sala de Cinema. 
Gerenciamento de uma Sala de Cinema, no Interior do Estado de Minas Gerais, com base no Custeio Direto

Alaerte Gomes de Assis Neto, Natani Andreza Jesus Oliveira, Fernando de Almeida Santos

Management of Cinema Room, in the State of Minas Gerais, based on Direct

Costing

\section{ABSTRACT}

The increasing competitiveness in the market, makes the acquisition ofe knowledge about cost management a differential over competitors. The objective of this research is to analyze the data obtained with the application of the direct costing method in a movie theater company so it is possible to reach a methodology to determine its costs. The present research was based on a documentary methodology with the use of information that had never been analyzed before, with the addition of descriptive and qualitative information, as well. To validate and exemplify the concepts presented, a case study took place with the application of a questionnaire and the direct costing method. It is concluded that, according to the methodology used, the manager started to gain information on what his direct and indirect expenses were in the analyzed period, along with the unit contribution margin of the sold items, and the company's balance point. The contribution of the work consists of adapting the direct costing method to the use of a movie theater, where the manager can seek to reduce expenses, increase the profit margin, and thereby contribute to the company's growth.

Keywords: Costs Management. Decision Making. Cinema Room.

Gestión de una sala de cine, en el estado de Minas Gerais, basada en costos

\section{RESUMEN}

Con la competitividad existente en el mercado, adquirir conocimiento sobre la gestión de costos es un diferencial sobre los competidores. El objetivo de esta investigación es analizar los datos obtenidos con la aplicación del método de costeo directo en una sala de cine para construir una forma de determinar sus costos. La metodología de investigación es documental, con el uso de información que no ha sido analizada, descriptiva y cualitativa. Para validar y ejemplificar los conceptos presentados, se utilizó un estudio de caso con la aplicación de un cuestionario y el método de costeo directo. Se concluye que, según la metodología utilizada, el gerente comenzó a tener información sobre cuáles fueron los gastos directos e indirectos en el período analizado, el margen de contribución unitaria de los artículos vendidos y el punto de equilibrio de la compañía. La contribución del trabajo consiste en adaptar el método de costeo directo para su uso en una sala de cine, donde el gerente puede tratar de reducir gastos, aumentar el margen de beneficio y, por lo tanto, contribuir al crecimiento de la empresa.

Palabras clave: Gestión de Costes. Toma de Decisiones. Cine. 
Gerenciamento de uma Sala de Cinema, no Interior do Estado de Minas Gerais, com base no

Custeio Direto

Alaerte Gomes de Assis Neto, Natani Andreza Jesus Oliveira, Fernando de Almeida Santos

\section{INTRODUÇÃO}

A interpretação do custo depende da atividade operacional de cada entidade. Santos (2019) descreve que para empresas comerciais, refere-se ao valor das baixas dos estoques das mercadorias vendidas. Quando se trata de empresas prestadoras de serviços, deve associar os custos da mão de obra, de materiais e outros gastos gerais. Nas indústrias, conforme destaca Marion (2019), os valores que compõem os custos de produção são matéria-prima, mão de obra etc.

A área de custos dispõe de mecanismos capazes de gerar informações úteis à tomada de decisão e, mesmo com esse tipo de informação disponível, nem todas as entidades utilizam essas ferramentas gerenciais. Isso pode afetar o resultado da empresa, pois sem o controle dos gastos deixa de formar preço de venda de maneira adequada ou de buscar reduções de custos com melhorias nos processos.

Cunha, Monteiro, Castanha, Menegali, Vieira e Cittadin (2017) destacam que a gestão de custos contribui para manutenção e crescimento da empresa, pois reduz os gastos e gera informações úteis ao processo de tomada de decisão.

Esta dificuldade em apurar custos é maior em microempresas e empresas de pequeno porte, em que há menor infraestrutura, portanto, o presente artigo busca responder ao seguinte problema de pesquisa: De que maneira o método de custeio direto pode auxiliar na gestão de custos em uma sala de cinema? Para tal, utilizou-se como objeto de pesquisa uma empresa de pequeno porte do interior de Minas Gerais.

O objetivo geral é analisar de que maneira o método de custeio direto pode identificar os gastos em uma sala de cinema do interior do Estado de Minas Gerais. Os objetivos específicos foram verificar como é realizada a classificação dos gastos na empresa, relatar o processo de aplicação e os resultados obtidos por meio da adoção do método de custeio direto, e demonstrar a relevância das informações gerenciais obtidas com a utilização desta metodologia.

Para o Sebrae (2018), as microempresas e empresas de pequeno porte possuem uma significativa relevância para o país representando 99\% de 6,4 milhões de 
Gerenciamento de uma Sala de Cinema, no Interior do Estado de Minas Gerais, com base no Custeio Direto Alaerte Gomes de Assis Neto, Natani Andreza Jesus Oliveira, Fernando de Almeida Santos

estabelecimentos, respondendo por $52 \%$ do total de empregos formais existentes no país. Acredita-se que a relevância deste trabalho está na utilização das informações geradas pelo método de custeio direto no processo de tomada de decisão em uma sala de cinema.

Ao realizar consultas no acervo de pesquisas virtuais da Biblioteca Digital de Teses e Dissertações (BDTD) e Periódicos CAPES (Coordenação de Aperfeiçoamento de Pessoal de Nível Superior), não foram encontrados estudos relacionados ao tema "aplicação método de custeio direto em uma sala de cinema". Com essa lacuna acadêmica no Brasil, em relação ao tema proposto neste trabalho, buscou-se tornar o assunto de fácil entendimento e encontrar uma sala de cinema que possuísse informações dos gastos ocorridos nos últimos doze meses.

Ocorreu a realização desta pesquisa, utilizando-se uma abordagem exploratória e qualitativa, com o levantamento de todos os gastos ocorridos na empresa durante 0 período analisado, bem como uma aplicação de um questionário enviado ao empresário. E, ainda, a implantação do método de custeio direto para analisar os benefícios obtidos.

Para ter argumentos sobre a validade teórica da pesquisa, realizou-se uma consulta em 11/03/2019 no acervo de pesquisas científicas da Biblioteca Digital de Teses e Dissertações, nos quais foram encontrados 128 trabalhos que apresentaram as palavras "custeio direto" e 244 pesquisas que envolveram "sala de cinema". Ao ampliar a pesquisa para os Periódicos CAPES, localizaram-se 309 trabalhos envolvendo "custeio direto" e 1.093 trabalhos sobre "sala de cinema". Entretanto, em ambas as bases, nenhuma pesquisa que relacionasse os dois assuntos.

Após essa verificação, percebeu-se que existe uma lacuna acadêmica no Brasil em relação a esse tema. Com isso, não foi possível escrever subtópicos realizando um panorama de estudos científicos anteriores sobre o assunto. 
Gerenciamento de uma Sala de Cinema, no Interior do Estado de Minas Gerais, com base no Custeio Direto Alaerte Gomes de Assis Neto, Natani Andreza Jesus Oliveira, Fernando de Almeida Santos

\section{REFERENCIAL TEÓRICO}

O referencial deste trabalho foi composto pela definição de microempresas e empresas de pequeno porte, classificação de custos e métodos de custeio.

\subsection{Definição de Microempresas e Empresas de Pequeno Porte}

As empresas são classificadas de acordo com o faturamento bruto anual e número de empregados. As pequenas e médias empresas não têm obrigação de divulgar suas demonstrações financeiras, elaborando informações para atender demandas gerais dos usuários externos.

Segundo a Lei Complementar no 123/2006 atualizada, consideram-se microempresas ou empresas de pequeno porte a sociedade empresária ou simples, e empresário a que se refere o artigo da Lei oㅜ 10.406/2002, devidamente registrado no Registro de Empresas Mercantis ou no Registro Civil de Pessoas Jurídicas, tendo receita bruta anual como: microempresa até $R \$ 360.000,00$ e empresa de pequeno porte acima de $R \$ 360.000,00$ até $R \$ 4.800 .000,00$ (Brasil, 2006). A Figura 1 apresenta outra forma de classificação de empresas, que consiste no critério de número de empregados, utilizado pelo Dieese:

\begin{tabular}{|c|c|c|}
\hline Porte/Setor & Indústria & Comércio e Serviços \\
\hline Microempresas & Com até 19 empregados & Até 9 empregados \\
\hline $\begin{array}{c}\text { Empresas de } \\
\text { Pequeno Porte }\end{array}$ & De 20 a 99 empregados & De 10 a 49 empregados \\
\hline Médias & De 100 a 499 empregados & De 50 a 99 empregados \\
\hline Grandes & Mais de 500 empregados & Mais de 100 empregados \\
\hline
\end{tabular}

Figura 1. Classificação das microempresas e empresas de pequeno porte com base no número de empregados

Fonte: SEBRAE (2017) - Adaptado pelos autores. 
Gerenciamento de uma Sala de Cinema, no Interior do Estado de Minas Gerais, com base no Custeio Direto Alaerte Gomes de Assis Neto, Natani Andreza Jesus Oliveira, Fernando de Almeida Santos

Pequenas e médias empresas são empresas que:

(a) não têm obrigação pública de prestação de contas; e

(b) elaboram demonstrações contábeis para fins gerais para usuários externos.

Exemplos de usuários externos incluem proprietários que não estão envolvidos na administração do negócio, credores existentes e potenciais, e agências de avaliação de crédito. (CPC PME, 2009).

De acordo com a Figura 2, em 2016, havia no Brasil 8.249 micro e pequenas empresas (MPE) exportadoras, número que cresceu 12,1\% em relação ao ano anterior. As MPE representam 38,0\% das organizações exportadoras do país em 2016, sendo composto por $13,1 \%$ referentes às microempresas e $24,9 \%$ às empresas de pequeno porte.

\begin{tabular}{|l|c|c|}
\hline \multicolumn{1}{|c|}{ Porte/Setor } & $\mathbf{2 0 1 5}$ & $\mathbf{2 0 1 6}$ \\
\hline Microempresas & 7.359 & 8.249 \\
\hline Média & 6.883 & 7.130 \\
\hline Grande & 5.353 & 5.415 \\
\hline Não classificada & 327 & 918 \\
\hline
\end{tabular}

Figura 2. Número de empresas exportadoras segundo porte das firmas

Fonte: SEBRAE (2017) - Adaptado pelos autores.

Com a Lei Complementar no $123 / 2006$ foi criado o modelo simplificado de tributação conhecido como SIMPLES (Sistema Integrado de Pagamento de Impostos e Contribuições das Microempresas e Empresas de Pequeno Porte). Esse método implantou a cobrança de impostos federais, estaduais, municipais e contribuições sociais em uma única guia, por meio de uma alíquota que depende do limite de faturamento e atividades da empresa (Brasil, 2006).

Santos, Anjos, Cavalcante e Monte (2016) observam que a informação contábil quando não gera benefícios aos seus usuários, perde seu sentido e passa a ser um custo adicional, no qual naturalmente, deve ser evitado. Mesmo a Interpretação Técnica Geral (ITG), 1000 representando um modelo contábil simplificado, e que tende a impor um custo menor comparado aos demais métodos, a principal questão é a sua 
Gerenciamento de uma Sala de Cinema, no Interior do Estado de Minas Gerais, com base no Custeio Direto Alaerte Gomes de Assis Neto, Natani Andreza Jesus Oliveira, Fernando de Almeida Santos

capacidade em gerar informações úteis aos gestores das microempresas e empresas de pequeno porte oferecendo benefícios maiores que seus gastos.

As microempresas e empresas de pequeno porte precisam realizar uma gestão eficiente para ocorrer uma melhora nos resultados e, com isso, administrar as atividades com maior profissionalismo.

\subsection{Classificação de Custos}

Para ocorrer uma compreensão sobre os métodos de custeio, definiu-se os seguintes conceitos: custo fixo, variável, direto e indireto.

Botelho (2006) destaca que a convivência empírica das pessoas com os custos demonstra um entendimento errôneo a respeito de algumas terminologias utilizadas pela contabilidade. Para esclarecer algumas dúvidas, torna-se necessário conceituar os termos mais utilizados.

Para analisar os custos, é indispensável à identificação e classificação desses de maneira correta, assim como a escolha mais adequada para alocação dos custos ao produto final. Com isso, Filgueira (2016) observa que é necessário analisar qual o tipo de informação se adequa as necessidades da organização.

Conforme afirma Bruni e Famá (2009), custos são os gastos referentes a bens ou serviços utilizados na produção de outros bens e serviços. Com isso, estão associados aos produtos e serviços elaborados pela instituição.

Para fins contábeis, o custo está relacionado com a aquisição de mercadorias para estoque (empresa comercial) ou insumos para fabricação de itens (empresa industrial). Padoveze (2016) destaca que os custos são associados aos produtos, posteriormente ativados quando os itens forem gerados. São todos os gastos ligados à área industrial da organização.

Com base na Figura 3, custos fixos são aqueles cujos valores são constantes independente do volume de produção da empresa. Um exemplo seria o aluguel da fábrica, que será cobrado um valor que não depende da quantidade produzida, e 
Gerenciamento de uma Sala de Cinema, no Interior do Estado de Minas Gerais, com base no Custeio Direto

Alaerte Gomes de Assis Neto, Natani Andreza Jesus Oliveira, Fernando de Almeida Santos

mesmo que não ocorra produção, o valor será o mesmo. Os custos variáveis, por sua vez, têm seu valor modificado em função do volume de produção da organização.

\begin{tabular}{|l|l|}
\hline \multicolumn{1}{|c|}{ Termos } & \multicolumn{1}{c|}{ Características } \\
\hline Custo Fixo & $\begin{array}{l}\text { Viceconti (2018) lembra que, os custos fixos são fixos em relação ao volume de } \\
\text { produção, entretanto, podem variar de valor ao longo do tempo. }\end{array}$ \\
\hline Custo Variável & $\begin{array}{l}\text { Segundo Warren, Reeve e Fess (2008), os custos variáveis são aqueles custos que } \\
\text { modificam no total proporcionalmente às mudanças no nível de atividade. }\end{array}$ \\
\hline Custo Direto & $\begin{array}{l}\text { Para Padoveze (2016), um custo deve ser considerado como direto quando se torna } \\
\text { possível verificar uma ligação direta com um determinado produto final, sendo capaz } \\
\text { de visualizá-lo e mensurá-lo. Bruni e Famá (2009) observam que os custos diretos são } \\
\text { aqueles incluídos de forma direta no cálculo dos produtos, tendo a propriedade de } \\
\text { serem mensuráveis de forma clara e objetiva, portanto, representam os materiais } \\
\text { diretos utilizados no processo produtivo e mão de obra direta. }\end{array}$ \\
\hline Custo Indireto & $\begin{array}{l}\text { Contrário aos custos diretos, Viceconti (2018) destaca que os custos indiretos são os } \\
\text { custos que dependem de cálculos, rateios e estimativas para serem alocados aos } \\
\text { produtos, ou seja, são apropriados de forma indireta. O parâmetro utilizado para estas } \\
\text { estimativas é chamado de rateio. }\end{array}$ \\
\hline
\end{tabular}

Figura 3. Definições de Custos

Fonte: Elaborado pelos autores.

Quanto maior a quantidade produzida, maior os custos variáveis, alterando de forma proporcionalmente direta em relação às variações produtivas que se relacionam. Também existe o custo direto, que pode ser fisicamente identificado em determinado segmento, ou seja, é possível estabelecer uma ligação direta com determinado produto final, tendo a capacidade de visualizá-lo no produto acabado e mensurar sua participação. Em relação aos custos indiretos, não podem ser alocados com clareza e objetividade aos itens produzidos, a outro segmento ou atividade operacional. Como não possuem condição de utilizar uma medida objetiva, qualquer alocação deve ser feita utilizando rateios.

Portanto, as organizações devem definir como realizam a apropriação dos custos fixos, variáveis, diretos e indiretos para analisar qual o método de custeio mais adequado as suas necessidades. 
Gerenciamento de uma Sala de Cinema, no Interior do Estado de Minas Gerais, com base no Custeio Direto Alaerte Gomes de Assis Neto, Natani Andreza Jesus Oliveira, Fernando de Almeida Santos

\subsection{Métodos de Custeio}

Este tópico se propõe a descrever o método de custeio por absorção, direto e activity based costing $(\mathrm{ABC})$.

Filgueira (2016) considera que o método de custeio é entendido como um conjunto de procedimentos, com diferentes abordagens de identificação dos custos, e cada método trata a classificação de custos de maneira específica. Corroborando, Silva (2014) descreve que os métodos de custeio consistem em definir como e quais custos serão levados em consideração no cálculo do custeio de cada item e na valorização do inventário.

De acordo com a Figura 4, o método de custeio por absorção apropria todos os custos produtivos aos bens e serviços. Esse método é caracterizado por utilizar os custos diretos e indiretos relacionados ao processo produtivo. A apropriação dos custos indiretos ocorre por meio do rateio.

O método de custeio por absorção é utilizado pela contabilidade financeira no balanço patrimonial e demonstração de resultado. Também é adotado pela auditoria externa para avaliação de estoques, mesmo não tendo critérios totalmente lógicos para realização dos rateios e não atendendo as necessidades dos administradores.

Já o custeio direto deve ser utilizado apenas para análises gerenciais, pois a legislação vigente impõe a aplicação do custeio por absorção para fins contábeis e fiscais. Nesta metodologia, os gastos variáveis são alocados ao item e os gastos fixos são considerados como despesas do resultado. Os custos fixos existem independente de ocorrer ou não produção e, com isso, não são considerados como custos de elaboração. As informações que são geradas com esta metodologia são essenciais para os administradores realizarem análises e determinar a saúde financeira da empresa.

$O$ custeio $A B C$ busca reduzir sensivelmente as distorções provocadas pela utilização do rateio nos custos indiretos, existindo um método que utiliza direcionadores de custos. Os direcionadores indicam a relação entre o consumo de recursos e as 
Gerenciamento de uma Sala de Cinema, no Interior do Estado de Minas Gerais, com base no Custeio Direto Alaerte Gomes de Assis Neto, Natani Andreza Jesus Oliveira, Fernando de Almeida Santos

atividades desenvolvidas. Após esse reconhecimento, busca-se identificar os produtos que consumiram essas atividades.

\begin{tabular}{|c|c|}
\hline $\begin{array}{l}\text { Métodos de } \\
\text { Custeio }\end{array}$ & Características \\
\hline Absorção & $\begin{array}{l}\text { Rosa (2006) destaca que no custeio por absorção, a totalidade dos custos, fixos e } \\
\text { variáveis são alocados aos itens. Os custos indiretos são distribuídos aos produtos } \\
\text { através da utilização do rateio, tais como quantidade produzida, hora de mão-de-obra } \\
\text { direta, etc. Para Pultz (2016) existe uma grande arbitrariedade nessa alocação, tendo } \\
\text { a particularidade dos processos produtivos e a impossibilidade de medição exata dos } \\
\text { custos indiretos. } \\
\text { Segundo Martins (2015) este método de custeio não é considerado como um } \\
\text { princípio contábil, mas um método nascido da própria contabilidade de custos. } \\
\text { Existem outras formas de avaliação de estoque, mas este ainda é adotado pela } \\
\text { contabilidade financeira, utilizada no balanço patrimonial e demonstração de } \\
\text { resultado como também, na maioria dos países, para balanço e lucro fiscal. A } \\
\text { auditoria externa também adota este método de custeio para avaliação de estoques, } \\
\text { mesmo não tendo critérios totalmente lógicos quanto ao rateio e não atendendo as } \\
\text { necessidades gerenciais. }\end{array}$ \\
\hline Direto & $\begin{array}{l}\text { Conforme afirma Viceconti (2018), o custeio direto é um tipo de metodologia que } \\
\text { considera como custo de produção apenas os custos variáveis incorridos. Os custos } \\
\text { fixos, pelo fato de existirem independente da produção, não são considerados como } \\
\text { custo de elaboração e sim como despesas, indo direto para o resultado. Bernardinelli, } \\
\text { Miyabara e Popadiuk (2000) observam que este método de custeio é utilizado, no } \\
\text { Brasil, somente para análises gerenciais, em função da legislação impor a utilização } \\
\text { do custeio por absorção para fins contábeis e fiscais. }\end{array}$ \\
\hline $\mathrm{ABC}$ & $\begin{array}{l}\text { Rosa (2006) considera o custeio baseado em atividades como um método que tem } \\
\text { por finalidade reduzir as distorções provocadas pelo rateio arbitrário dos custos } \\
\text { indiretos, utilizado pelos sistemas tradicionais. Logo, Brasil (2004) destaca que os } \\
\text { direcionadores contribuem para controlar a eficiência das atividades, permitindo aos } \\
\text { administradores visualizar quais atividades não agregam valor no processo produtivo, } \\
\text { e também contribui para avaliação dos centros de desempenhos das atividades. }\end{array}$ \\
\hline
\end{tabular}

Figura 4. Definições dos Métodos de Custeio

Fonte: Elaborado pelos autores. 
Gerenciamento de uma Sala de Cinema, no Interior do Estado de Minas Gerais, com base no

Custeio Direto

Alaerte Gomes de Assis Neto, Natani Andreza Jesus Oliveira, Fernando de Almeida Santos

O estudo utilizou a aplicação do método de custeio direto para obter informações como a margem de contribuição unitária dos itens comercializados e o ponto de equilíbrio da entidade. A margem de contribuição demonstra o valor adicionado pela empresa ao produto, já os gastos variáveis informam a contribuição de terceiros (fornecedores, empregados, entre outros). Esse dado é fundamental no processo de tomada de decisão, pois fornece informações como qual item oferece a melhor e pior margem. Esse cálculo consiste na diferença entre o preço de venda unitário e os gastos variáveis de cada produto. Ponto de equilíbrio é quando as receitas e os gastos de uma organização são iguais, não existindo lucro ou prejuízo.

Padoveze (2016) destaca que a margem de contribuição representa o lucro variável da empresa. Consiste na diferença entre preço de venda unitário e os custos e despesas variáveis por unidade de produto ou serviço. O significado é que para cada unidade vendida, a empresa terá um determinado lucro. Müller e Imeton (2017) observam que caso a margem do produto comercializado não seja analisada de forma correta, pode comprometer os resultados da empresa, em função de uma percepção equivocada sobre a lucratividade de determinado item, acreditando que esteja fornecendo benefícios e na verdade pode estar trazendo prejuízos.

Filgueira (2016) considera que com a utilização de um estudo do ponto de equilíbrio, analisa-se a quantidade mínima que deve ser vendida para que a empresa consiga honrar seus compromissos. Segundo Padoveze (2016), a informação sobre o ponto de equilíbrio da instituição, tanto global como por item individual, é muito importante, pois identifica o nível mínimo de atividade em que a empresa ou cada divisão deve operar.

Araújo (2015) considera que alguns métodos são mais indicados para instrumentos gerenciais, outros para relatórios externos, existindo uma visão de curto e longo prazo. Com isso, entende-se que não existe um método de custeio ideal a ser utilizado na empresa, independente da finalidade. Assim, dependendo do objetivo e tipo de informação a ser obtida, deve-se escolher um ou até mais de um método de custeio para ser utilizado. 
Gerenciamento de uma Sala de Cinema, no Interior do Estado de Minas Gerais, com base no Custeio Direto Alaerte Gomes de Assis Neto, Natani Andreza Jesus Oliveira, Fernando de Almeida Santos

Após descrever os tipos de custos e os métodos de custeio, percebe-se que essas informações são essenciais no processo de tomada de decisão em uma entidade que busca obter uma posição de destaque no mercado.

\section{METODOLOGIA}

Com o intuito de tornar a metodologia do trabalho mais clara e didática, utilizouse um fluxograma para descrever todas as etapas realizadas durante a coleta e análises das informações.

Conforme descrito na Figura 5, ocorreu a aplicação do estudo de caso em uma sala de cinema do interior de Minas Gerais.

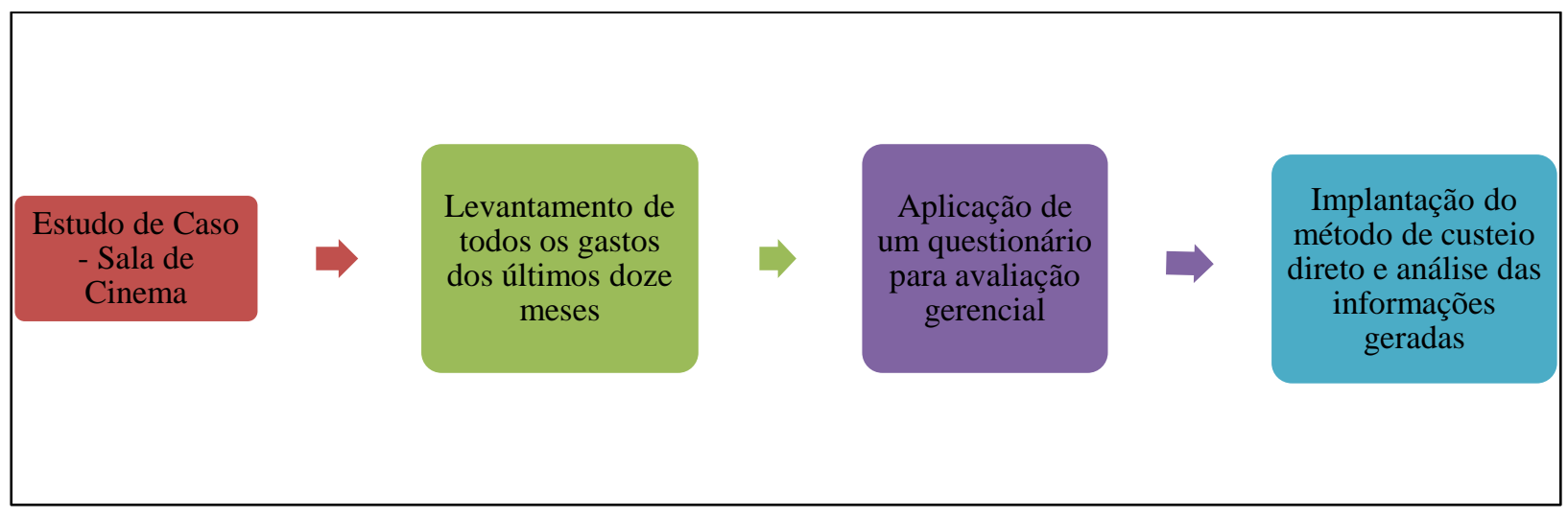

Figura 5. Fluxograma Etapas Metodologia

Fonte: Elaborado pelos autores.

Inicialmente, selecionou-se uma sala de cinema devido à carência de informações gerenciais que auxiliem no processo de tomada de decisão. Esta empresa foi fundada em 07 de julho de 2000, sendo a primeira sala de cinema da região. Após essa etapa, ocorreu o levantamento de todos os gastos ocorridos durante os últimos doze meses (março de 2018 até fevereiro de 2019) para iniciar a análise na organização. Também foi necessário avaliar por meio de um questionário quais eram as 
Gerenciamento de uma Sala de Cinema, no Interior do Estado de Minas Gerais, com base no Custeio Direto Alaerte Gomes de Assis Neto, Natani Andreza Jesus Oliveira, Fernando de Almeida Santos

informações que auxiliavam no processo de tomada de decisão e obter um entendimento das necessidades do administrador.

Com os dados coletados e depois de analisar as respostas do questionário, iniciou-se a implantação do método de custeio direto. Esta metodologia foi escolhida porque era a que mais se adequava a estrutura da entidade. A análise teve início na classificação de todos os gastos por plano de conta e realizada a média dos valores obtidos nos últimos doze meses.

A partir disso foram separados e analisados todos gastos diretos e indiretos para examinar quais produtos tinham as melhores e piores margens. Para calcular a margem de contribuição unitária, deve-se considerar o preço de venda e subtrair os gastos diretos. Após verificar a demanda do gestor, definiu-se que apenas o ponto de equilíbrio contábil atendia as necessidades e não foi calculado o ponto de equilíbrio financeiro e econômico.

No cálculo do ponto de equilíbrio contábil, considerou-se o total dos gastos indiretos divido pelo percentual da margem de contribuição.

De acordo com Yin (2010), o estudo de caso como método de pesquisa é utilizado em várias situações, contribuindo para o conhecimento de fenômenos individuais, grupais, organizacionais, sociais, políticos e relacionados. Os estudos de caso podem ser encontrados na economia, investigando a estrutura de um determinado setor industrial ou a economia de uma cidade. Em todas as situações, a necessidade diferenciada dos estudos de caso surge do desejo de entender os fenômenos sociais complexos. Corroborando, Marconi e Lakatos (2017) afirmam que existe o princípio de que qualquer caso estudado em profundidade pode representar muitos outros. O estudo de caso analisa determinados indivíduos, profissões, grupos e condições, buscando encontrar generalizações.

Além disso, utilizaram-se relatórios e planilhas fornecidas pelo administrador, contendo dados que não haviam sido tabulados e analisados anteriormente. Marconi e Lakatos (2017) descrevem que, na pesquisa documental, a fonte da coleta de dados está restrita aos documentos, constituindo o que se denomina de fontes primárias. 
Gerenciamento de uma Sala de Cinema, no Interior do Estado de Minas Gerais, com base no Custeio Direto Alaerte Gomes de Assis Neto, Natani Andreza Jesus Oliveira, Fernando de Almeida Santos

Esta pesquisa foi descritiva, onde os fatos foram verificados, relacionados e ponderados sem sofrer nenhuma interferência do pesquisador. Para corroborar e exemplificar, aplicou-se um questionário para avaliação gerencial. Este questionário possuiu dez questões fechadas e foi encaminhado ao gestor da sala de cinema, buscando verificar seu conhecimento sobre Custos, Métodos de Custeio e Controles Gerenciais.

Andrade (2010) destaca que na pesquisa descritiva, os fatos são observados, registrados, analisados, classificados e interpretados, sem nenhuma interferência do pesquisador. Um ponto importante na coleta de dados é que ocorra a utilização de uma técnica padronizada, como a aplicação de um questionário. Este questionário deve ser elaborado partindo do pressuposto que o informante não pode receber nenhuma informação adicional do pesquisador. Dessa maneira, as perguntas elaboradas e utilizadas devem ser claras e objetivas, tendo preferência por perguntas fechadas.

A pesquisa também pode ser caracterizada como qualitativa, pois os dados obtidos dependeram da utilização das metodologias de pesquisa, do referencial teórico que apresentou o assunto e a seleção da amostra.

Para Gil (2017), a análise qualitativa depende de vários fatores, tais como a natureza dos dados obtidos, a dimensão da amostra, os instrumentos de pesquisa e os pressupostos teóricos que norteiam a análise. Define-se como um processo que reduz e categoriza os dados, interpretando e gerando relatórios.

Com todas as informações obtidas, a empresa passou a buscar maneiras de otimizar o resultado e o administrador passou a receber relatórios adequados as suas necessidades e que auxiliam no processo de tomada de decisão.

\section{ANÁLISE DOS DADOS OBTIDOS}

O presente trabalho mostra as análises dos dados obtidos e, para tal, fez-se necessário a aplicação de um questionário. 
Gerenciamento de uma Sala de Cinema, no Interior do Estado de Minas Gerais, com base no Custeio Direto Alaerte Gomes de Assis Neto, Natani Andreza Jesus Oliveira, Fernando de Almeida Santos

Esse foi desenvolvido no primeiro semestre do ano de 2019, no mês de abril, quando buscou analisar quais eram as informações utilizadas no processo de tomada de decisão que permitiram um melhor entendimento sobre as necessidades do gestor da sala de cinema do interior do estado de Minas Gerais.

As respostas colhidas foram tabuladas, descritas e comentadas para ocorrer um maior entendimento, conforme o Figura 6.

\begin{tabular}{|l|c|c|}
\hline \multicolumn{1}{|c|}{ Perguntas } & Sim & Não \\
\hline 1- Ocorre a utilização de algum método de custeio na empresa? & () & $(\mathrm{X})$ \\
\hline 2- Existe o controle de todos os gastos ocorridos no período analisado? & $(\mathrm{X})$ & $(\mathrm{)}$ \\
\hline 3- A empresa separa quais foram os gastos fixos e variáveis? & $(\mathrm{)}$ & $(\mathrm{X})$ \\
\hline $\begin{array}{l}\text { 4- O gestor recebe informações sobre margem de contribuição dos produtos } \\
\text { comercializados e ponto de equilíbrio da empresa? }\end{array}$ & () & $(\mathrm{X})$ \\
\hline 5- Existem informações sobre horas-homens e insumos? & $(\mathrm{X})$ & $($ ) \\
\hline 6- A empresa possui controle de estoque? & $(\mathrm{X})$ & $($ ) \\
\hline 7- Existem controles gerenciais para verificar o resultado do período? & $(\mathrm{X})$ & $($ ) \\
\hline 8- Ocorre a escrituração regular em livros contábeis? & $(\mathrm{X})$ & $(\mathrm{)}$ \\
\hline 9- A contabilidade fiscal é utilizada pelos gestores? & $(\mathrm{X})$ & $($ ) \\
\hline $\begin{array}{l}\text { 10- Existe a necessidade de obter mais informações úteis ao processo de tomada } \\
\text { de decisão? }\end{array}$ & $(\mathrm{X})$ & $($ ) \\
\hline
\end{tabular}

Figura 6. Questionário aplicado ao gestor da sala de cinema

Fonte: CREPALDI, 2018 - Adaptado pelos autores.

A primeira questão proposta no questionário foi com o objetivo de obter informações sobre a utilização de algum método de custeio na empresa, entretanto o administrador não utiliza uma metodologia relacionada ao assunto. Com essa resposta, percebe-se uma necessidade de obter mais informações sobre um assunto relevante na gestão de qualquer organização. Na pergunta de número dois, existe um controle de todos os gastos ocorridos no período analisado.

Já na terceira resposta relacionada à separação dos gastos fixos e variáveis, a resposta foi negativa quanto a esse assunto. Na quarta pergunta o gestor não recebe 
Gerenciamento de uma Sala de Cinema, no Interior do Estado de Minas Gerais, com base no Custeio Direto Alaerte Gomes de Assis Neto, Natani Andreza Jesus Oliveira, Fernando de Almeida Santos

relatórios contendo informações sobre margem de contribuição e ponto de equilíbrio. Essas informações seriam úteis no processo de tomada de decisão.

A resposta foi positiva quanto à quinta pergunta. As informações sobre horashomens são utilizadas para analisar qual o gasto mensal da empresa com folha de pagamento, realizar o cálculo do valor da hora trabalhada e buscar maneiras de como otimizar o trabalho da equipe. Já o controle de insumos é utilizado para que seja realizado um planejamento de compras baseado nos filmes que serão exibidos no complexo.

Em relação à sexta questão, a entidade possui controle de estoque. Esse controle existe principalmente para evitar que ocorram fraudes, onde todo o estoque é conferido no final de cada dia e comparado com o sistema para analisar as divergências. Sendo que essas divergências são reportadas ao gestor e analisadas posteriormente. Na sétima pergunta, a empresa possui uma demonstração de resultado do exercício gerencial. Com essa demonstração, analisa-se o resultado obtido, quais foram os gastos mais relevantes e maneiras de reduzi-los.

Para a oitava questão relacionada à escrituração regular em livros contábeis, o gestor informou que a empresa possui todas as demonstrações contábeis exigidas pela legislação. Na nona pergunta prevaleceu a resposta positiva, onde o administrador utiliza as informações fiscais para análise de indicadores financeiros e valor de mercado da empresa.

Na décima pergunta, o administrador relatou que existe a necessidade de obter mais informações que auxiliem no processo de tomada de decisão.

Além da aplicação deste questionário, também foi realizado um estudo de caso, com a aplicação do método de custeio direto para realizar um controle dos gastos ocorridos no período analisado e gerar informações úteis ao processo de tomada de decisão.

Para implementação deste método de custeio, ocorreu a separação dos gastos diretos e indiretos de bilheteria e bomboniere tendo como base relatórios e planilhas fornecidas pelo gestor com todos os gastos ocorridos no período de março/2018 até 
Gerenciamento de uma Sala de Cinema, no Interior do Estado de Minas Gerais, com base no Custeio Direto Alaerte Gomes de Assis Neto, Natani Andreza Jesus Oliveira, Fernando de Almeida Santos

fevereiro/2019. Para calcular a margem de contribuição unitária, deve-se considerar o preço de venda e subtrair os gastos diretos de cada item. No cálculo do percentual da margem, considera a margem de contribuição unitária dividida pelo preço de venda e multiplicada por 100.

De acordo com a Tabela 1, na sala de cinema são comercializados ingressos para filmes em 2D e 3D, tendo a opção de ser inteira ou meia entrada. As distribuidoras para liberarem os filmes para a sala de cinema analisada neste estudo, exigem $50 \%$ do faturamento de bilheteria. Com isso, qualquer ingresso comercializado possui uma margem de contribuição de $50 \%$.

Tabela 1

Aplicação do Custeio Direto - Gastos Diretos (Bilheteria)

\begin{tabular}{lllll}
\hline $\begin{array}{l}\text { Tipo } \\
\text { Ingresso }\end{array}$ & Preço de Venda & Gasto Direto & $\begin{array}{l}\text { Margem de } \\
\text { Contribuição Unitária }\end{array}$ & $\begin{array}{l}\text { Margem de } \\
\text { Contribuição } \\
\text { Unitária }(\%)\end{array}$ \\
\hline $3 D-$ Inteira & $\mathrm{R} \$ 28,00$ & $\mathrm{R} \$ 14,00$ & $\mathrm{R} \$ 14,00$ & $50 \%$ \\
$3 \mathrm{D}-$ Meia & $\mathrm{R} \$ 14,00$ & $\mathrm{R} \$ 7,00$ & $\mathrm{R} \$ 7,00$ & $50 \%$ \\
$2 \mathrm{D}-$ Inteira & $\mathrm{R} \$ 24,00$ & $\mathrm{R} \$ 12,00$ & $\mathrm{R} \$ 12,00$ & $50 \%$ \\
$2 \mathrm{D}-$ Meia & $\mathrm{R} \$ 12,00$ & $\mathrm{R} \$ 6,00$ & $\mathrm{R} \$ 6,00$ & $50 \%$ \\
\hline
\end{tabular}

Nota. Fonte: Elaborado pelos autores.

A seguir apresentam-se todos os itens comercializados na bomboniere da empresa, preço de venda, gasto direto e margem de contribuição unitária. Na Tabela 2 e no Gráfico 1, as informações foram classificadas por ordem decrescente da margem de contribuição unitária (\%). 
Gerenciamento de uma Sala de Cinema, no Interior do Estado de Minas Gerais, com base no Custeio Direto Alaerte Gomes de Assis Neto, Natani Andreza Jesus Oliveira, Fernando de Almeida Santos

Tabela 2

Aplicação do Custeio Direto - Gastos Diretos (Bomboniere)

\begin{tabular}{lcccc}
\hline Produto & $\begin{array}{l}\text { Preço de } \\
\text { Venda }\end{array}$ & Gasto Direto & $\begin{array}{l}\text { Margem de } \\
\text { Contribuição Unitária }\end{array}$ & $\begin{array}{c}\text { Margem de } \\
\text { Contribuição } \\
\text { Unitária (\%) }\end{array}$ \\
\hline Pipoca Grande & $\mathrm{R} \$ 9,00$ & $\mathrm{R} \$ 0,45$ & $\mathrm{R} \$ 8,55$ & $95 \%$ \\
Pipoca Pequena & $\mathrm{R} \$ 5,00$ & $\mathrm{R} \$ 0,32$ & $\mathrm{R} \$ 4,68$ & $94 \%$ \\
Pipoca Balde & $\mathrm{R} \$ 13,00$ & $\mathrm{R} \$ 0,98$ & $\mathrm{R} \$ 12,02$ & $92 \%$ \\
Pipoca Júnior & $\mathrm{R} \$ 4,00$ & $\mathrm{R} \$ 0,36$ & $\mathrm{R} \$ 3,64$ & $91 \%$ \\
Chá & $\mathrm{R} \$ 5,00$ & $\mathrm{R} \$ 1,25$ & $\mathrm{R} \$ 3,75$ & $75 \%$ \\
Chocolate Baton & $\mathrm{R} \$ 2,00$ & $\mathrm{R} \$ 0,59$ & $\mathrm{R} \$ 1,41$ & $71 \%$ \\
Água & $\mathrm{R} \$ 4,00$ & $\mathrm{R} \$ 1,21$ & $\mathrm{R} \$ 2,79$ & $70 \%$ \\
Chocolate Kit-Kat & $\mathrm{R} \$ 6,00$ & $\mathrm{R} \$ 1,85$ & $\mathrm{R} \$ 4,15$ & $69 \%$ \\
Confeito M\&M & $\mathrm{R} \$ 5,00$ & $\mathrm{R} \$ 1,59$ & $\mathrm{R} \$ 3,41$ & $68 \%$ \\
Mentos & $\mathrm{R} \$ 3,00$ & $\mathrm{R} \$ 1,12$ & $\mathrm{R} \$ 1,88$ & $63 \%$ \\
Halls & $\mathrm{R} \$ 2,00$ & $\mathrm{R} \$ 0,78$ & $\mathrm{R} \$ 1,22$ & $61 \%$ \\
Refrigerante $290 \mathrm{ml}$ & $\mathrm{R} \$ 6,00$ & $\mathrm{R} \$ 2,34$ & $\mathrm{R} \$ 3,66$ & $61 \%$ \\
Chocolate Laka & $\mathrm{R} \$ 3,00$ & $\mathrm{R} \$ 1,20$ & $\mathrm{R} \$ 1,80$ & $60 \%$ \\
Kapo & $\mathrm{R} \$ 4,00$ & $\mathrm{R} \$ 1,67$ & $\mathrm{R} \$ 2,33$ & $58 \%$ \\
Chocolate Suflair & $\mathrm{R} \$ 6,00$ & $\mathrm{R} \$ 2,69$ & $\mathrm{R} \$ 3,31$ & $55 \%$ \\
Batata Sensação & $\mathrm{R} \$ 6,00$ & $\mathrm{R} \$ 2,85$ & $\mathrm{R} \$ 3,15$ & $53 \%$ \\
Refrigerante $310 \mathrm{ml}$ & $\mathrm{R} \$ 5,00$ & $\mathrm{R} \$ 2,35$ & $\mathrm{R} \$ 2,65$ & $53 \%$ \\
Refrigerante $450 \mathrm{ml}$ & $\mathrm{R} \$ 5,00$ & $\mathrm{R} \$ 2,35$ & $\mathrm{R} \$ 2,65$ & $53 \%$ \\
Confeito M\&M Gr & $\mathrm{R} \$ 5,00$ & $\mathrm{R} \$ 2,57$ & $\mathrm{R} \$ 2,43$ & $49 \%$ \\
Refrigerante $600 \mathrm{ml}$ & $\mathrm{R} \$ 7,00$ & $\mathrm{R} \$ 3,69$ & $\mathrm{R} \$ 3,31$ & $47 \%$ \\
Bombom & $\mathrm{R} \$ 1,00$ & $\mathrm{R} \$ 0,58$ & $\mathrm{R} \$ 0,42$ & $42 \%$ \\
Cerveja Heineken & $\mathrm{R} \$ 7,00$ & $\mathrm{R} \$ 4,05$ & $\mathrm{R} \$ 2,95$ & $21 \%$ \\
Refrigerante $220 \mathrm{ml}$ & $\mathrm{R} \$ 2,00$ & $\mathrm{R} \$ 1,59$ & $\mathrm{R} \$ 0,41$ & $13 \%$ \\
Batata Stax & $\mathrm{R} \$ 16,00$ & $\mathrm{R} \$ 13,91$ & &
\end{tabular}

Nota. Fonte: Elaborado pelos autores.

Com base na Figura 7, nota-se que as maiores margens dos itens de bombobiere estão nas pipocas (balde, grande, júnior, pequena). Com a obtenção dessa informação, o cinema passou a focar na venda de combos (pipoca com refrescos) para otimização do resultado. 
Gerenciamento de uma Sala de Cinema, no Interior do Estado de Minas Gerais, com base no Custeio Direto Alaerte Gomes de Assis Neto, Natani Andreza Jesus Oliveira, Fernando de Almeida Santos

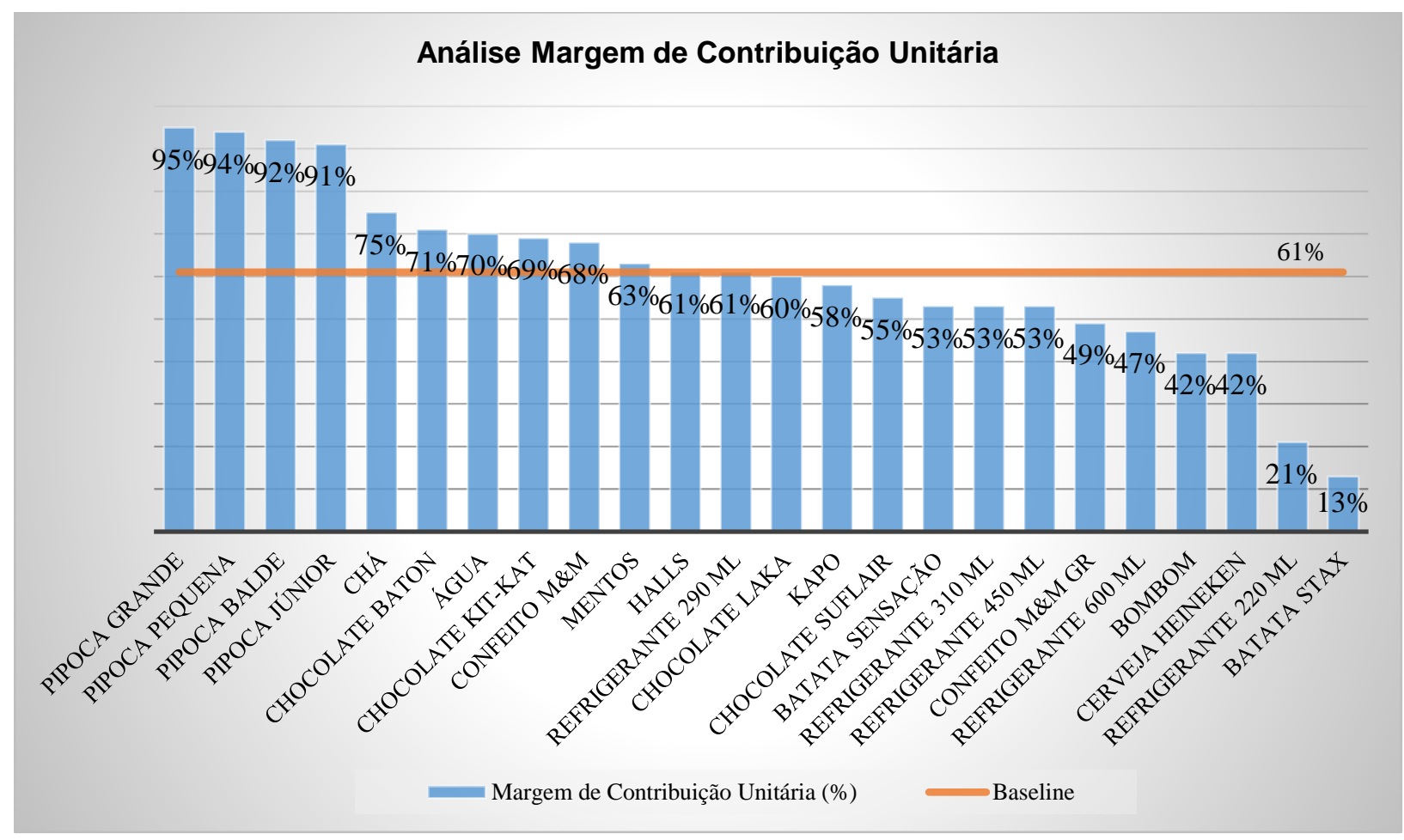

Figura 7: Gráfico da Análise Margem de Contribuição Unitária (\%)

Fonte: Elaborado pelos autores.

Os itens comercializados na bomboniere têm uma margem de contribuição unitária média de $61 \%$ (somou-se todos os percentuais das margens e o valor foi dividido pelo número de itens, ou seja, $1.456 \%$ dividido por 24 ), sendo chamada de baseline no gráfico (Figura 7).

A Tabela 3 apresenta análise sobre os gastos indiretos, considerando a soma de todos os valores separados por plano de conta durante o período de março/2018 até fevereiro/2019, e o montante foi dividido por doze meses. As informações foram classificadas por ordem decrescente do valor médio referente ao gasto indireto. 
Gerenciamento de uma Sala de Cinema, no Interior do Estado de Minas Gerais, com base no
Custeio Direto

Tabela 3

Aplicação do Custeio Direto - Gastos Indiretos

(continuação)

\begin{tabular}{|c|c|c|}
\hline Plano de Conta & Valor Médio & Descrição \\
\hline $\begin{array}{l}\text { Mão de Obra } \\
\text { bilheteria/bomboniere }\end{array}$ & $\mathrm{R} \$ 8.591,48$ & $\begin{array}{l}\text { Este valor é composto por } R \$ 5.670,38 \text { de salário da equipe } \\
\text { operacional e } R \$ 2.921,10 \text { de encargos projetados para férias, } \\
13^{\circ} \text { salário e rescisão da equipe (34\% multiplicado por } R \$ \\
8.591,48)\end{array}$ \\
\hline Simples Nacional & $R \$ 6.860,32$ & A empresa é optante pelo Simples Nacional \\
\hline Aluguel & $\mathrm{R} \$ 5.938,69$ & $\begin{array}{l}\text { O imóvel onde a empresa está localizada é no centro da cidade, } \\
\text { sendo alugado }\end{array}$ \\
\hline $\begin{array}{l}\text { Mão de Obra } \\
\text { coordenação }\end{array}$ & $\mathrm{R} \$ 5.739,21$ & $\begin{array}{l}\text { Este valor é composto por } R \$ 3.787,88 \text { de salário do } \\
\text { coordenador da equipe operacional e um colaborador do } \\
\text { departamento financeiro e } R \$ 1.951,33 \text { de encargos projetados } \\
\text { para férias, } 13^{\circ} \text { salário e rescisão da equipe ( } 34 \% \text { multiplicado } \\
\text { por } R \$ 5.739,21 \text { ) }\end{array}$ \\
\hline $\begin{array}{l}\text { Serviços de } \\
\text { manutenção }\end{array}$ & $\mathrm{R} \$ 4.819,28$ & $\begin{array}{l}\text { Neste item são considerados todos os prestadores de serviços } \\
\text { como sistema utilizado pela empresa, manutenção do projetor, } \\
\text { entre outros }\end{array}$ \\
\hline $\begin{array}{l}\text { Depreciação das } \\
\text { instalações }\end{array}$ & $\mathrm{R} \$ 4.709,85$ & $\begin{array}{l}\text { A depreciação gerencial é a mesma que a fiscal, onde todos os } \\
\text { itens imobilizados da empresa possuem nota fiscal }\end{array}$ \\
\hline Eletricidade & $\mathrm{R} \$ 3.394,06$ & $\begin{array}{l}\text { Este gasto é relevante principalmente pela utilização do projetor } \\
\text { para exibir os filmes, geladeiras para armazenar os refrescos, } \\
\text { pipoqueira e ar condicionado }\end{array}$ \\
\hline $\begin{array}{l}\text { Outros impostos e } \\
\text { taxas }\end{array}$ & $\mathrm{R} \$ 2.797,79$ & $\begin{array}{l}\text { Considera-se neste plano de conta Imposto de Renda Retido na } \\
\text { Fonte (IRRF), Imposto sobre Serviço de Qualquer Natureza } \\
\text { (ISS), e Instituto Nacional do Seguro Social (INSS) }\end{array}$ \\
\hline $\begin{array}{l}\text { Imposto sobre } \\
\text { Circulação de } \\
\text { Mercadorias e } \\
\text { Serviços (ICMS) }\end{array}$ & $\mathrm{R} \$ 2.690,76$ & $\begin{array}{l}\text { O valor gasto com ICMS é referente ao débito e crédito entre a } \\
\text { compra e venda dos produtos de bomboniere }\end{array}$ \\
\hline Mão de Obra Diretoria & $\mathrm{R} \$ 2.647,34$ & Este valor é referente ao pró-labore recebido pelo empresário \\
\hline Despesas Diversas & $\mathrm{R} \$ 2$ & São todos os gastos que não ocorrem com frequência \\
\hline Contador & $\mathrm{R} \$ 1.904,18$ & $\begin{array}{l}\text { A contabilidade é terceirizada, utilizando um escritório para } \\
\text { realizar toda a escrituração contábil/fiscal/pessoal }\end{array}$ \\
\hline $\begin{array}{l}\text { Jornais, revistas, } \\
\text { rádio, entre outros }\end{array}$ & $\mathrm{R} \$ 1.823,50$ & $\begin{array}{l}\text { A empresa realiza propagandas nos principais meios de } \\
\text { comunicação da cidade }\end{array}$ \\
\hline Despesas bancárias & $\mathrm{R} \$ 954,90$ & $\begin{array}{l}\text { Neste plano de conta são lançadas todas as despesas } \\
\text { bancárias e taxas de cartões cobradas pela utilização das } \\
\text { máquinas do PagSeguro }\end{array}$ \\
\hline Material de limpeza & $\mathrm{R} \$ 607,96$ & $\begin{array}{l}\text { O maior consumo de material de limpeza é na manutenção da } \\
\text { sala de exibição }\end{array}$ \\
\hline Campanhas de Filmes & $\mathrm{R} \$ 604,82$ & $\begin{array}{l}\text { Este valor é referente as campanhas publicitárias de filmes que } \\
\text { serão exibidos no cinema }\end{array}$ \\
\hline Patrocínio e outros & $\mathrm{R} \$ 603,97$ & $\begin{array}{l}\text { Existe a realização de patrocínios em alguns eventos que } \\
\text { ocorrem na cidade, e a empresa também patrocina alguns } \\
\text { atletas }\end{array}$ \\
\hline Internet & $\mathrm{R} \$ 541,04$ & $\begin{array}{l}\text { Foi considerada a internet utilizada, e } 0 \text { valor pago para } \\
\text { manutenções do site }\end{array}$ \\
\hline
\end{tabular}


Gerenciamento de uma Sala de Cinema, no Interior do Estado de Minas Gerais, com base no

Custeio Direto

Alaerte Gomes de Assis Neto, Natani Andreza Jesus Oliveira, Fernando de Almeida Santos

\begin{tabular}{|c|c|c|}
\hline & & \\
\hline Plano de Conta & Valor Médio & Descrição \\
\hline $\begin{array}{l}\text { Imposto Predial e } \\
\text { Territorial Urbano } \\
\text { (IPTU) }\end{array}$ & $\mathrm{R} \$ 420,54$ & $\begin{array}{l}\text { A empresa realizou o pagamento do IPTU do imóvel alugado, e } \\
\text { de quatro terrenos próprios (comprados para construir um novo } \\
\text { complexo). Este pagamento foi em parcela única, mas na } \\
\text { análise gerencial foi considerado o valor médio de } R \$ 420,54\end{array}$ \\
\hline Peças de reposição & $\mathrm{R} \$ 388,54$ & $\begin{array}{l}\text { São gastos realizados com itens de manutenção como peças } \\
\text { para pipoqueira, lâmpadas, entre outros }\end{array}$ \\
\hline Telefo & 07 & A empresa possui telefone fixo e linhas móveis \\
\hline Água e Esgoto & 20 & Este gasto é alto por causa da área do imóvel \\
\hline $\begin{array}{l}\text { Seguros de imóvel e } \\
\text { instalações }\end{array}$ & 5,55 & $\begin{array}{l}\text { O pagamento do seguro do imóvel foi realizado em parcela } \\
\text { única. } \mathrm{Na} \text { análise gerencial foi considerado o valor médio de } \\
\mathrm{R} \$ 255,55\end{array}$ \\
\hline Uniforme & $\mathrm{R} \$ 224,74$ & Apenas a equipe operacional utiliza uniforme \\
\hline $\begin{array}{l}\text { Filme (custo fixo da } \\
\text { programação) }\end{array}$ & $R \$ 1$ & Este gasto é com fretes dos filn \\
\hline $\begin{array}{l}\text { Segurança e } \\
\text { monitoramento de } \\
\text { alarme }\end{array}$ & $\mathrm{R} \$ 147,21$ & Ocorre a terceirização da segurança (alarme e câmeras) \\
\hline Material de escritório & 34 & O maior consumo é com sulfit \\
\hline $\begin{array}{l}\text { Viagem, locomoção e } \\
\text { alimentação }\end{array}$ & $\mathrm{R}$ & $\begin{array}{l}\text { A empresa possui este gasto quando o empresário vai em } \\
\text { algum evento relacionado a exibição cinematográfica }\end{array}$ \\
\hline $\begin{array}{l}\text { Agência de } \\
\text { publicidade }\end{array}$ & $R \$ 130,00$ & $\begin{array}{l}\text { A comunicação é terceirizada, fornecendo todo auxílio na parte } \\
\text { visual da empresa }\end{array}$ \\
\hline $\begin{array}{l}\text { Exame admissional / } \\
\text { demissional }\end{array}$ & $\mathrm{R} \$ 110,00$ & $\begin{array}{l}\text { Por ser uma atividade em que a equipe operacional trabalha no } \\
\text { período vespertino e noturno, existe uma rotatividade média de } \\
\text { doze meses }\end{array}$ \\
\hline $\begin{array}{l}\text { Associação Comercial } \\
\text { de Guaxupé }\end{array}$ & $\mathrm{R} \$ 68,64$ & $\begin{array}{l}\text { Esta associação organiza eventos e palestra para capacitação } \\
\text { dos empresários e colaboradores das empresas associadas }\end{array}$ \\
\hline Seguro Funcionários & & Todos os colaboradores possuem seguro de vida \\
\hline $\begin{array}{l}\text { Festas e } \\
\text { confraternizações }\end{array}$ & $\mathrm{R} \$ 59,15$ & $\begin{array}{l}\text { O empresário sempre realiza confraternizações com a equipe } \\
\text { para melhorar o clima organizacional }\end{array}$ \\
\hline Cartório & ,30 & Gasto com autenticação de documentos \\
\hline Total & $\mathrm{R} \$ 60.373,65$ & 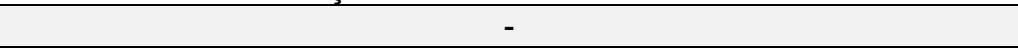 \\
\hline
\end{tabular}

Nota. Fonte: Elaborado pelos autores.

$\mathrm{Na}$ Tabela 4, descreve-se o ponto de equilíbrio da empresa. O faturamento durante os meses analisados consiste em $60 \%$ bilheteria e $40 \%$ bomboniere. Com isso, os gastos indiretos seguiram essas porcentagens para cálculo do ponto de equilíbrio. 
Gerenciamento de uma Sala de Cinema, no Interior do Estado de Minas Gerais, com base no Custeio Direto Alaerte Gomes de Assis Neto, Natani Andreza Jesus Oliveira, Fernando de Almeida Santos

Tabela 4

Aplicação do Custeio Direto - Ponto de Equilíbrio

\begin{tabular}{lll}
\hline Custeio Direto & Fórmula & Cálculo \\
\hline Ponto de Equilíbrio & $\mathrm{PE}=$ Gastos Indiretos / \% Média MCU & $\mathrm{PE}=\mathrm{R} \$ 36.224,19 / 50 \%=$ \\
Contábil Bilheteria & Bilheteria & $\mathrm{R} \$ 72.448,38$ \\
Ponto de Equilíbrio & $\mathrm{PE}=$ Gastos Indiretos /\% Média MCU & $\mathrm{PE}=\mathrm{R} \$ 24.149,46 / 61 \%=$ \\
Contábil Bomboniere & Bomboniere & $\mathrm{R} \$ 39.806,80$ \\
\hline
\end{tabular}

Nota. Fonte: Elaborado pelos autores.

Com base na Tabela 4, para realizar o cálculo do Ponto de Equilíbrio Contábil de Bilheteria ocorreu a divisão dos gastos indiretos relacionados à bilheteria de $\mathrm{R} \$ 36.224,19$ (Total Gasto Indireto de $\mathrm{R} \$ 60.373,65 \times 60 \%$ ), pelo percentual médio das margens de contribuições com as vendas de ingressos (descrito na Tabela 1) de 50\%. Com isso, chegou a um ponto de equilíbrio contábil de bilheteria de $R \$ 72.448,38$.

Para realizar o cálculo do ponto de equilíbrio contábil de bomboniere, seguiu-se a mesma metodologia dividindo os gastos indiretos relacionados à bomboniere de $\mathrm{R} \$$ 24.149,46 (Total Gasto Indireto de $\mathrm{R} \$ 60.373,65 \times 40 \%$ ), pelo percentual médio das margens de contribuições com as vendas de bomboniere (descrito no Gráfico 1) de $61 \%$. Foi obtido um ponto de equilíbrio contábil de bomboniere de $\mathrm{R} \$ 39.806,80$.

Com esta análise, o método de custeio direto conseguiu gerar informações que auxiliem na gestão de custos em uma sala de cinema como quais foram os gastos diretos e indiretos, margem de contribuição de cada produto vendido e o ponto de equilíbrio de bilheteria e bomboniere. Tendo estes dados, o gestor consegue realizar uma administração mais profissional do negócio, focando na venda dos itens com as melhores margens e buscando obter reduções para otimização do resultado.

Em relação as limitações, destacam-se que este método não pode ser utilizado para fins contábeis e não permite analisar quais atividades não agregam valor na produção dos itens. 
Gerenciamento de uma Sala de Cinema, no Interior do Estado de Minas Gerais, com base no Custeio Direto Alaerte Gomes de Assis Neto, Natani Andreza Jesus Oliveira, Fernando de Almeida Santos

\section{CONSIDERAÇÕES FINAIS}

Neste trabalho, definiu-se microempresas e empresas de pequeno porte, demonstrando que as organizações podem ser classificadas de acordo com 0 faturamento e também pelo número de colaboradores. Foram descritas as principais características dos custos fixos, variáveis, diretos e indiretos. Ademais, apresentou-se o custeio por absorção, direto e ABC.

Conclui-se que o administrador não utilizava um método de custeio na sala de cinema do interior do Estado de Minas Gerais e, assim, não tinha relatórios com informações sobre margem de contribuição e ponto de equilíbrio.

Com a aplicação do método de custeio direto, a empresa passou a gerar informações que auxiliem na gestão de custos, como quais foram os gastos diretos e indiretos, verificando que os ingressos comercializados têm uma margem de contribuição média de $50 \%$ e os itens de bomboniere de $61 \%$, necessitando de um faturamento de $R \$ 72.448,38$ para atingir o ponto de equilíbrio de bilheteria e $R \$$ $\mathrm{R} \$ 39.806,80$ para obter o ponto de equilíbrio de bomboniere. O gestor passou a ter maior controle dos gastos ocorridos, focando as campanhas comerciais nos itens com as maiores margens para otimizar o resultado.

Observa-se que a metodologia para identificação de custos pode-se aplicar em outras salas com o mesmo perfil, porém recomenda-se ampliar a pesquisa para outras empresas a fim de identificar possíveis diferenças.

\section{REFERÊNCIAS}

Andrade, M. M. (2010). Introdução à Metodologia do Trabalho Científico (10a ed.). São Paulo: Atlas.

Araújo, J. G. (2015). Utilização das Informações Gerenciais para Tomada de Decisão: Um Estudo Exploratório no Arranjo Produtivo Local de Confecção do Estado de Pernambuco (Dissertação de Mestrado). Universidade Federal de Pernambuco UFPE, Recife, PE, Brasil. Recuperado de: 
Gerenciamento de uma Sala de Cinema, no Interior do Estado de Minas Gerais, com base no Custeio Direto Alaerte Gomes de Assis Neto, Natani Andreza Jesus Oliveira, Fernando de Almeida Santos

<https://repositorio.ufpe.br/bitstream/123456789/16073/1/JULIANA\%20GON\%C3\% 87ALVES\%20DE\%20ARA\%C3\%9AJO.pdf>. Acesso em: 09 set. 2019.

Bdtd. Biblioteca Digital Brasileira de Teses e Dissertações. Acervo de periódicos. Recuperado de: <http://bdtd.ibict.br/vufind/Search/Results?lookfor=aplica\%C3\%A7\%C3\%A3o+m\%C $3 \%$ A9todo+de+custeio+direto+em+uma+sala+de+cinema\&type=AllFields $>$. Acesso em: 09 set. 2019.

Bernardinelli, A., Miyabara, W., \& Popadiuk, S. (2000). Métodos de Custo Adotados pela Indústria Farmacêutica e suas Influências na Decisão de Promover um Produto. Revista de Administração Mackenzie, 01(01), 127-142. Recuperado de: $<$ http://editorarevistas.mackenzie.br/index.php/RAM/article/view/7/7>. Acesso em: 09 set. 2019.

Botelho, E. M. (2006). Custeio Baseado em Atividades - ABC: Uma Aplicação em um Organização Hospitalar Universitária (Tese de Doutorado). Universidade de São Paulo - USP, São Paulo, SP, Brasil. Recuperado de: <http://www.teses.usp.br/teses/disponiveis/12/12139/tde-10042008-102523/ptbr.php>. Acesso em: 09 set. 2019.

Brasil, S. A. S. (2004). Custeio Baseado em Atividades Aplicado à Prestação de Serviços Médicos de Radiologia. Revista Contabilidade \& Finanças, 15(34), 63-79. Recuperado de: <https://doi.org/10.1590/S1519-70772004000100005>. Acesso em: 09 set. 2019.

Bruni, A. L., \& Famá, R. (2009). Gestão de Custos e Formação de Preços: Com Aplicação na Calculadora HP 12C (5a ed.). São Paulo: Atlas.

Capes. Periódicos Capes. Acervo de periódicos. Recuperado de: $<$ http://www.periodicos.capes.gov.br/?option=com_pmetabusca\&mn $=88 \& \mathrm{smn}=88 \& \mathrm{t}$ ype=m\&metalib=aHR0cHM6Ly9ybnAtcHJpbW8uaG9zdGVkLmV4bGlicmlzZ3JvdXA uY29tL3ByaW1vX2xpYnJhcnkvbGlid2ViL2FjdGlvbi9zZWFyY2guZG8\%2FZHNjbnQ9 MCZwY0F2YWIsYWJpbHR5TW9kZT1mYWxzZSZmcmJnPSZzY3Auc2Nwcz1wcmlt b19jZW50cmFsX211bHRpcGxIX2ZIJnRhYj1kZWZhdWx0X3RhYiZjdD1zZWFyY2gm bW9kZT1CYXNpYyZkdW09dHJ1ZSZpbmR4PTEmZm49c2VhcmNoJnZpZD1DQVB FU19WMQ\%3D\%3D\&buscaRapidaTermo=aplica\%C3\%A7\%C3\%A3o+m\%C3\%A9t odo+de+custeio+direto+em+uma+sala+de+cinema>. Acesso em: 09/set./2019.

Comitê de Pronunciamentos Contábeis - CPC. CPC-PME: Contabilidade para Pequenas e Médias Empresas. Recuperado de: <http://static.cpc.aatb.com.br/Documentos/392_CPC_PMEeGlossario_R1_rev\%201 1_alt.pdf>. Acesso em: 09 set. 2019. 
Gerenciamento de uma Sala de Cinema, no Interior do Estado de Minas Gerais, com base no Custeio Direto Alaerte Gomes de Assis Neto, Natani Andreza Jesus Oliveira, Fernando de Almeida Santos

Crepaldi, S. A. (2018). Contabilidade Rural: Uma Abordagem Decisorial (8a ed.). São Paulo: Atlas.

Cunha, P. M., Monteiro, J. J., Castanha, E. T., Menegali, M. V., Vieira, A. C. P., \& Cittadin, A. (2017). O Uso do Custeio Variável para Gestão de uma Vinícola Catarinense. Congresso Brasileiro de Custos, 24. Recuperado de: $<$ https://anaiscbc.emnuvens.com.br/anais/article/view/4376>. Acesso em: 09 set. 2019.

Filgueira, N. C. (2016). Análise do Método de Custeio Aplicado em uma Mineradora no Estado do Pará e Proposições de Melhoria (Dissertação de Mestrado). Universidade Federal de Pernambuco - UFPE, Recife, PE, Brasil. Recuperado de: $<$ https://repositorio.ufpe.br/bitstream/123456789/20337/1/disserta\%C3\%A7\%C3\%A 30\%20biblioteca.pdf>. Acesso em 09 set /2019.

Gil, A. C. (2017). Como Elaborar Projetos de Pesquisa (6a ed.). São Paulo: Cortez.

Lei Complementar o 123 (2006). Dispõe sobre estatuto nacional da microempresa e empresa de pequeno porte. Recuperado de: <http://www.planalto.gov.br/ccivil_03/LEIS/LCP/Lcp123.htm>. Acesso em: 09 set. 2019.

Marion, J. C. (2019). Análise das Demonstrações Contábeis (8a ed.). São Paulo: Atlas.

Martins, E. (2015). Contabilidade de Custos (11a ed.). São Paulo: Atlas.

Müller, L. S., \& Imeton, L. S. (2017). A Análise da margem de contribuição como ferramenta gerencial para tomada de decisão: Um estudo de caso do D'Lilian Restaurante. Congresso Brasileiro de Custos, 24. Recuperado de: $<$ https://anaiscbc.emnuvens.com.br/anais/article/view/4328>. Acesso em: 09 set. 2019.

Padoveze, C. L. (2016). Contabilidade de Custos: Teoria, Prática, Integração com Sistemas de Informações (ERP). (1a ed.). São Paulo: Cengage.

Pultz, F. D. (2016). A utilização do Método de Custeio Baseado por Atividades para o Gerenciamento Estratégico de Custos de um Laticínio: Estudo de Caso em um Laticínio do Interior do Estado de São Paulo (Dissertação de Mestrado). Universidade de São Paulo - USP, São Paulo, SP, Brasil. Recuperado de: $<$ http://www.teses.usp.br/teses/disponiveis/74/74134/tde-03112016-150905/ptbr.php>. Acesso em: 09 set. 2019. 
Gerenciamento de uma Sala de Cinema, no Interior do Estado de Minas Gerais, com base no Custeio Direto

Alaerte Gomes de Assis Neto, Natani Andreza Jesus Oliveira, Fernando de Almeida Santos

Rosa, E. B. (2006). Indicadores de Desempenho e Sistema ABC: O Uso de Indicadores para uma Gestão Eficaz do Custeio e das Atividades de Manutenção (Tese de Doutorado). Universidade de São Paulo - USP, São Paulo, SP, Brasil. Recuperado de: $\quad<$ http://www.teses.usp.br/teses/disponiveis/3/3136/tde-05092006-124335/ptbr.php>. Acesso em: 09 set. 2019.

Santos, J. O. (2019). Valuation: Um Guia Prático (2a ed.). São Paulo: Saraiva.

Santos, M. A. C., Anjos, L. C. M., Cavalcante, P. R. N., \& Monte, P. A. (2016). ITG 1000, Risk Detection and Accounting Information: A Theoretical Analysis on the Cost versus Benefit for Micro and Small Enterprises. Revista Brazilian Business Review, 13(3), 48-69. Recuperado de: <https://www.redalyc.org/articulo.oa?id=123045332003 >. Acesso em: 09/set./2019.

Sebrae. As Micro e Pequenas Empresas nas Exportações Brasileiras: 2009 - 2016 Brasil. Recuperado de: <http://www.bibliotecas.sebrae.com.br/chronus/ARQUIVOS_CHRONUS/bds/bds.nsf /54159d7ce6a88bfbbf9d32a0a9d58f3b/\$File/7796.pdf>. Acesso em: 09 set. 2019.

Sebrae. Pequenos Negócios em Números. (s.d.) Recuperado de: <http://www.sebrae.com.br/sites/PortalSebrae/ufs/sp/sebraeaz/pequenos-negociosem-numeros,12e8794363447510VgnVCM1000004c00210aRCRD>. Acesso em: 09 set. 2019.

Sebrae. Qual a Receita Bruta e Número de Empregados para MEI, ME e EPP. Recuperado de: <https://blog.sebrae-sc.com.br/numero-de-empregados-receitabruta-para-mei-me-epp/>. Acesso em: 09 set. 2019.

Silva, C. A. (2014). Integração do método de custeio variável à demonstração financeira de resultados: um estudo de caso em uma indústria de médio porte (Dissertação de Mestrado). Universidade de São Paulo - USP, São Paulo, SP, Brasil. Recuperado de: $\quad$ https://www.teses.usp.br/teses/disponiveis/3/3136/tde-16122014160043/publico/DISS_SILVACA.pdf>. Acesso em: 09 set. 2019.

Viceconti, P., \& Neves, S. (2018). Contabilidade de Custos: Um Enfoque Direto e Objetivo (12a ed.). São Paulo: Saraiva.

Warren, C. S., Reeve, J. M., \& Fess, P. E. (2008). Contabilidade Gerencial (2a ed.). São Paulo: Thomson.

Yin, R. K. (2010). Estudo de Caso: Planejamento e Métodos (4a ed.). Porto Alegre: Bookman. 
Gerenciamento de uma Sala de Cinema, no Interior do Estado de Minas Gerais, com base no Custeio Direto

Alaerte Gomes de Assis Neto, Natani Andreza Jesus Oliveira, Fernando de Almeida Santos

Data de Submissão: 09/09/2019

Data de Aceite: 02/06/2020 